\title{
Rare pulmonary diseases and orphan drugs: where do we stand and where are we going to?
}

\author{
Sergio Harari ${ }^{1}$, Marc Humbert ${ }^{2,3,4}$, Francesco Blasi ${ }^{5}$, Harold R. Collard ${ }^{6}$, \\ Marco Matucci-Cerinic ${ }^{7}$, Gerald Simonneau ${ }^{2,3,4}$, Carlo Vancheri ${ }^{8}$, \\ Athol U. Wells ${ }^{9}$ and Vincent Cottin ${ }^{10,11}$
}

\begin{abstract}
Affiliations: ${ }^{1}$ U.0. di Pneumologia e Terapia Semi-Intensiva Respiratoria, Servizio di Fisiopatologia Respiratoria ed Emodinamica Polmonare, Ospedale San Giuseppe, MultiMedica IRCCS, Milan, Italy. ${ }^{2}$ Univ. Paris-Sud, Faculté de Médecine, Le Kremlin-Bicêtre, France. ${ }^{3} \mathrm{AP}-\mathrm{HP}$, Centre de Référence de l'Hypertension Pulmonaire Sévère, Département Hospitalo-Universitaire (DHU) Thorax Innovation (TORINO), Service de Pneumologie, Hôpital de Bicêtre, Le Kremlin-Bicêtre, France. 'UMR_S 999, Univ. Paris-Sud, INSERM, Laboratoire d'Excellence (LabEx) en Recherche sur le Médicament et l'Innovation Thérapeutique (LERMIT), Centre Chirurgical Marie Lannelongue, Le Plessis-Robinson, France. ${ }^{5}$ Dept of Pathophysiology and Transplantation, University of Milan, IRCCS Fondazione Ospedale Maggiore, Policlinico Cà Granda, Milan, Italy. ${ }^{6}$ University of California San Francisco, San Francisco, CA, USA. ${ }^{7}$ Dept of Experimental and Clinical Medicine, Division of Rheumatology AOUC, School of Medicine, University of Florence, Florence, Italy. ${ }^{8}$ Dept of Clinical and Experimental Biomedicine, Section of Respiratory Diseases, Regional Center for Interstitial and Rare Lung Diseases, University of Catania, Policlinico "G. Rodolico", Catania, Italy. "Royal Brompton and Harefield NHS Foundation Trust, London, UK. ${ }^{10}$ Hospices Civils de Lyon, Hôpital Louis Pradel, Service de Pneumologie, Centre de Référence National des Maladies Pulmonaires Rares, Lyon, France. ${ }^{11}$ Université de Lyon, Université Lyon I, INRA, UMR754 INRA, Vetagrosup EPHE IFR 128, Lyon, France.
\end{abstract}

Correspondence: Sergio Harari, U.O. di Pneumologia e Terapia Semi-Intensiva Respiratoria, Servizio di Fisiopatologia Respiratoria ed Emodinamica Polmonare, Ospedale San Giuseppe, MultiMedica IRCCS, Via San Vittore 12, 20123 Milan, Italy. E-mail: shararidilpolmone.it

0

@ERSpublications

Updates on rare pulmonary diseases from the 6th International Meeting on Pulmonary Rare Diseases and Orphan Drugs http://ow.ly/PYUCC

Rare diseases are a major problem for the patients who suffer from them, for their families and for selected specialists involved in their management. In addition, they cause economic, social and public health problems that should be acknowledged and discussed by the medical and scientific community. Because of the rarity of these illnesses, the experience of most physicians is usually limited to a few cases. Nevertheless, the essential steps in the diagnosis and management of a patient who is suspected to have, for example, an interstitial lung disease or pulmonary hypertension, should be common knowledge, as these diseases are uncommon, but not, in fact, exceedingly rare [1-3]. Furthermore, rare presentations of frequent lung diseases (e.g. rare thoracic cancers, severe asthma, and emphysema with $\alpha_{1}$-antitrypsin deficiency) and the most typical rare pulmonary diseases can share similar aspects, both in research and in their clinical management [4].

Rare diseases also constitute an interesting challenge for the development of new trials and for the evaluation of surrogate end-points, as demonstrated in recent years with forced vital capacity in idiopathic pulmonary fibrosis trials [5-7] and with the criticism of the 6-min walk test in pulmonary hypertension studies [8].

Received: June 222015 | Accepted: June 252015

Conflict of interest: Disclosures can be found alongside the online version of this article at err.ersjournals.com

Provenance: Publication of this peer-reviewed article was sponsored by F. Hoffman-La Roche Ltd, Basel, Switzerland (principal sponsor, European Respiratory Review issue 137).

Copyright OERS 2015. ERR articles are open access and distributed under the terms of the Creative Commons Attribution Non-Commercial Licence 4.0. 
The possible gap between the efficacy of drugs tested in clinical trials and their effectiveness in real life represents another aspect of particular interest in the evaluation of orphan drugs, as indeed it is in the evaluation of drugs used in more common conditions. The strong links between basic research and clinical management can be witnessed in the way many centres around the world already manage rare pulmonary diseases. It represents an advanced model of translational approach to modern medicine.

In order to discuss these topics, the International Meeting on Pulmonary Rare Diseases and Orphan Drugs has been held in Milan (Italy) every other year since 2005. It is the only European meeting dedicated to all the various types of rare pulmonary diseases, both parenchymal and vascular. The 6th Congress was endorsed by the European Respiratory Society (ERS), and was held on February 27 and 28, 2015 (see [9] for more information and slide presentations), for the Rare Disease Day (February 28, 2015) and also in light of the fact that the Universal Exposition 2015 is taking place in Milan this year. The next Congress will be held on February 24 and 25, 2017. The success of this Congress is based on its many profiles (international, translational and clinical), which bring together scientists from different fields of expertise (from pulmonary hypertension to lymphangioleiomyomatosis, idiopathic pulmonary fibrosis, etc.), providing them with a valuable opportunity to encompass a broad range of insights within the area of respiratory medicine.

The scientific programmes of the different editions of the meeting were designed to build bridges between physicians specialised in the management of different respiratory diseases, which had the common feature of being rare or corresponding to rare presentations of common lung diseases. The translational approach has been improved in recent years, bridging basic research and clinical investigation, and the meeting has become more and more international. The way to provide new insights into science and clinical care is the sharing of knowledge and the exchange of information with regard to different areas of clinical and basic research in respiratory medicine, among experts with varied specialisms in pulmonary medicine.

An international scientific committee, comprising eminent physicians from Europe and the USA, suggested the topics for the programme. In 2015, the committee included F. Blasi, H.R. Collard, V. Cottin, M. Humbert, M. Matucci-Cerinic, G. Simonneau, C. Vancheri, A.U. Wells and S. Harari (Congress Chair).

In the past 20 years, there have been significant advances in the knowledge and management of rare pulmonary diseases. This has been made possible by several factors, including: 1) the better definition of some of the diseases (e.g. idiopathic pulmonary fibrosis and pulmonary arterial hypertension); 2) the collaborative effort of research carried out by the respiratory medicine community; 3) the process of information of the public, physicians and patients; 4) the coordinated action against rare diseases implemented by health authorities in several western countries and at a European level; 5) the significant role of patients' associations, which have raised awareness and created funds, allowing independent clinical trials; and, last but not least, 6) the investments made by major pharmaceutical companies, fostered by orphan drug legislation.

The increasing scientific interest in rare pulmonary diseases within the entire European medical community can be witnessed in the continuous rise in the number of scientific publications related to these topics and in the growing attention paid to this field in the publications of the ERS [1, 10]. In particular, in the past few years, the European Respiratory Review (ERR) has dedicated a lot of space to rare pulmonary diseases and orphan drugs.

In this issue of the $E R R$, selected papers from the Milan meeting are published and give an overview of important areas of pulmonary research. CAPPELli et al. [11] provide a comprehensive review of the new advances in the pathogenesis, diagnosis and treatment of interstitial lung disease associated with systemic sclerosis. ADIR et al. [12] discuss the epidemiology, pathogenic mechanisms and treatment approaches of the different causes of pulmonary hypertension in the setting of chronic myeloproliferative disorders: chronic thromboembolic pulmonary hypertension, pre-capillary pulmonary hypertension mimicking pulmonary arterial hypertension and drug-induced pulmonary hypertension. CAminati et al. [13] add important information to our knowledge regarding pitfalls in methodologies and data interpretation in epidemiological studies on idiopathic pulmonary fibrosis and analyse the main issues that should be carefully considered when comparing different studies. MARGARITOPOULOs et al. [14] present an overview of what's new in smoking-related lung diseases. HARARI and CAminati [15] discuss the role of real-life studies on idiopathic pulmonary fibrosis and the gap between randomised controlled clinical trials and everyday practice. We hope you will enjoy reading these articles and we look forward welcoming you in Milan at the next International Meeting on Pulmonary Rare Diseases and Orphan Drugs in February 2017.

\section{References}

1 Harari S, Lau EM, Tamura Y, et al. Rare (pulmonary) disease day: “feeding the breath, energy for life!" Eur Respir J 2015; 45: 297-300. 
2 Spagnolo P, du Bois RM, Cottin V. Rare lung disease and orphan drug development. Lancet Respir Med 2013; 1: 479-487.

3 Cordier JF, Cottin V. Orphan lung diseases from definition to organisation of care. In: Cottin V, Cordier JF, Richeldi L, eds. Orphan Lung Diseases: A Clinical Guide to Rare Lung Disease. London, Springer-Verlag, 2015; pp. 1-3.

4 Harari S, Humbert M, Cottin V. Future perspectives on rare pulmonary diseases and rare presentations of common disorders. Eur Respir Rev 2013; 22: 199-201.

5 Raghu G, Collard HR, Anstrom KJ, et al. Idiopathic pulmonary fibrosis: clinically meaningful primary endpoints in phase 3 clinical trials. Am J Respir Crit Care Med 2012; 185: 1044-1048.

6 du Bois RM, Nathan SD, Richeldi L, et al. Idiopathic pulmonary fibrosis: lung function is a clinically meaningful endpoint for phase III trials. Am J Respir Crit Care Med 2012; 186: 712-715.

7 Wells AU, Behr J, Costabel U, et al. Hot of the breath: mortality as primary end-point in IPF treatment trials: the best is the enemy of the good. Thorax 2012; 67: 938-940.

8 Mathai SC, Puhan MA, Lam D, et al. The minimal important difference in the 6-minute walk test for patients with pulmonary arterial hypertension. Am J Respir Crit Care Med 2012; 186: 428-433.

9 6th International Meeting on Pulmonary Rare Diseases and Orphan Drugs. www.pulmonaryrarediseases.com Date last accessed: July 30, 2015.

10 Harari S, Cottin V, Humbert M. Global effort against rare and orphan diseases. Eur Respir Rev 2012; 21: 171-172.

11 Cappelli S, Bellando Randone S, Camiciottoli G, et al. Interstitial lung disease in systemic sclerosis: where do we stand? Eur Respir Rev 2015; 24: 411-419.

12 Adir Y, Elia D, Harari S. Pulmonary hypertension in patients with chronic myeloproliferative disorders. Eur Respir Rev 2015; 24: 400-410.

13 Caminati A, Madotto F, Cesana G, et al. Epidemiological studies in idiopathic pulmonary fibrosis: pitfalls in methodologies and data interpretation. Eur Respir Rev 2015; 24: 436-444.

14 Margaritopoulos GA, Vasarmidi E, Jacob J, et al. Smoking and interstitial lung diseases. Eur Respir Rev 2015; 24: 428-435.

15 Harari S, Caminati A. Idiopathic pulmonary fibrosis: from clinical trials to real-life experiences. Eur Respir Rev 2015; 24: 420-427. 